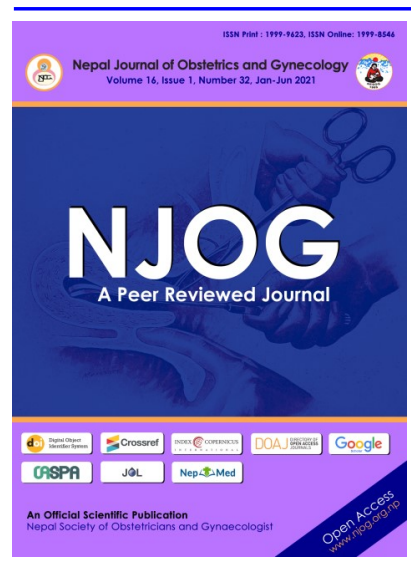

CORRESPONDENCE

Dr Amar Nath Chaudhary

Department of OBGYN, Nobel Medical College, Biratnagar, Nepal

Email: amarbs000@gmail.com; Phone: +977-9862037557

Received: May 1, 2020 Accepted: May 20, 2021

\section{Citation:}

Chaudhary AN, Baral G, Shrestha P, Bhanshakarya R. Laparoscopic pelvic adnexal surgery in Nobel Medical College. Nep J Obstet Gynecol. 2021;16 (32):65-68. DOI: https:// doi.org/10.3126/ njog.v16i1.37522

\title{
Laparoscopic pelvic adnexal surgery in Nobel Medical College
}

Amar Nath Chaudhary, Gehanath Baral, Prajmi Shrestha, Rakina Bhanshakarya

Department of OBGYN, Nobel Medical College, Biratnagar, Nepal

\section{ABSTRACT}

Aim: To share early experience of gynaecological laparoscopic surgeries for adnexal masses in Nobel Medical College and Teaching Hospital (NMCTH).

Methods: This is a observational descriptive study in the Department of Obstetrics and Gynaecology of Nobel Medical College, Biratnagar for one year in 2019-2020. All the patients undergoing laparoscopic pelvic surgeries for adnexal masses were analysed for indication, type of procedure, complications and histopathological diagnosis.

Results: A total of 123 laparoscopic surgeries were performed. Preoperative diagnosis in most of the cases was adnexal mass followed by adnexal evaluation for subfertility. The common surgical procedure was cystectomy followed by salpingo-oophorectomy in $80 \%$ of cases. The most common histopathological diagnosis was mature cystic teratoma $(42 ; 34 \%)$ followed by endometriosis $(29 ; 23.8 \%)$ and cystadenoma $(25 ; 20.3 \%)$.

Conclusions: Adnexal evaluation and surgical treatment were performed with laparoscopy. The common pathologies were mature cystic teratoma, endometriosis and ovarian cystadenomas.

Keywords: adnexal mass, dermoid, endometriosis, laparoscopy

\section{INTRODUCTION}

Laparoscopy, a modern surgical technique where small openings are created in abdominal wall to visualize and operate for various pathology in intra-abdominal organs, started early in 1920, initially in animals like dog and later in human in $1910 .{ }^{1}$ Gynaecological laparoscopy surgery started in Nepal with tubal ligation in 1971 in Maternity Hospital in Kathmandu and later on evolved to other major gynaecological surgeries. ${ }^{2}$ It was started in Nobel medical college (NMCTH) from 2015 and it is evolving day by day. Though there are several advantages of this procedure it is not widely practiced due to high cost in our setup, unavailability of full set of instruments and properly trained staffs. Minimal invasive surgery has become increasingly popul- ar among both doctors and patients for diagnostic as well as operative laparoscopy. NMCTH is one of the few institutes in eastern Nepal where minimal invasive gynaecological procedure is being regularly performed. This study is aimed to find out different adnexal pathologies in laparoscopic surgery.

\section{METHODS}

This was an observational descriptive study done in Nobel Medical College and Teaching Hospital (NMCTH), Biratnagar, Nepal from $2019 / 08 / 18$ to $2020 / 08 / 17$. All patients from emergency ward and gynaecological outdoor consultation requiring laparoscopic surgery were enrolled in this study. Cases requiring morcellator were not enrolled. Ethical approval was taken from eth- 
ical review board of the institute. Routine consent form was assured from the patient record.

A routine pre-operative assessment for diagnostic and surgical fitness purpose was done including pelvic ultrasonography, tumour markers and computed tomography of abdomen and pelvis wherever required. All the patients with adnexal mass with normal tumour markers were admitted one day prior to surgery and all the procedures were done under general anaesthesia in the lithotomy Trendelenburg position. Abdomen was opened with $10 \mathrm{~mm}$ supra or infraumbilical incision with creation of pneumoperitoneum. Two $5 \mathrm{~mm}$ handling port were opened in bilateral flank whenever required. Routine postoperative care given including intravenous antibiotics for at least 24 hours followed by oral antibiotics for total 7 days. The patients of diagnostic laparoscopy were discharged after 24 hour and other patients were discharged on $2^{\text {nd }}$ or $3^{\text {rd }}$ post-operative day and followed from time of admission to minimum 2 weeks till histopathology reports obtained.

\section{RESULTS}

There were 122 cases during one year of study period with age range of 12 to 77 year; and $79 \%$ were from 25 to 40 years. [Table-1]

Table-1: Age group distribution $(\mathrm{N}=122)$

\begin{tabular}{ccc}
\hline Age group (years) & $\mathrm{N}$ & $\%$ \\
\hline$<20$ & 3 & 2.5 \\
$20-25$ & 12 & 9.8 \\
$25-30$ & 23 & 18.9 \\
$30-35$ & 31 & 25.4 \\
$35-40$ & 24 & 19.7 \\
$40-45$ & 13 & 10.7 \\
$>45$ & 16 & 13.1 \\
\hline
\end{tabular}

Preoperative diagnosis in most of the cases was adnexal mass $(108 ; 87.8 \%)$ followed by evaluation for subfertility $(12 ; 9.8 \%)$ and abdomino-pelvic mass (2; $1.1 \%)$. The common surgical procedure was cystectomy followed by salpingo-oophorectomy in $80 \%$ of cases. [Table-2] Among the dermoid group $71.4 \%$ underwent cystectomy and $26.2 \%$ salpingooophorectomy while in the endometriotic group only $48.3 \%$ underwent cystectomy and $31 \%$ salpingooophorectomy.
Table-2: Types of surgery performed $(\mathrm{N}=122)$

\begin{tabular}{lll}
\hline Types of surgery & $\mathrm{N}$ & $\%$ \\
\hline Laparoscopic cystectomy & 71 & 57.7 \\
Lap. Salpingo-oophorectomy & 28 & 22.8 \\
Diagnostic laparoscopy & 8 & 6.5 \\
Tubal ligation & 6 & 4.9 \\
Myomectomy & 4 & 3.3 \\
Puncture of cyst & 3 & 2.4 \\
Laparoscopic oophorectomy & 2 & 1.6 \\
\hline
\end{tabular}

The most common histopathological diagnosis was mature cystic teratoma $(42 ; 37.2 \%)$ followed by endometriosis $(29 ; 25.7 \%)$ and cystadenoma (25; $22.1 \%)$. Nine patients lost for follow up and histopathology report could not be retrieved from lab. [Table-3]

Table-3: Histopathology report $(\mathrm{N}=113)$

\begin{tabular}{lcc}
\hline Histopathology & $\mathrm{N}$ & $\%$ \\
\hline Mature cystic teratoma & 42 & 37.2 \\
Endometriosis & 29 & 25.7 \\
Cystadenoma mucinous & 14 & 12.4 \\
Cystadenoma serous & 11 & 9.7 \\
Tubal block & 6 & 5.3 \\
Cystic corpus luteum & 4 & 3.5 \\
Fibroid & 4 & 3.5 \\
Granulosa cell tumor & 1 & 0.9 \\
Para tubal cyst & 1 & 0.9 \\
Ectopic & 1 & 0.9 \\
\hline
\end{tabular}

Mean age of the patients with diagnosis dermoid was $35 \pm 8.9$ years and that for the endometriosis was $30.97 \pm 7.6$ where $47.7 \%$ (20) of dermoid and $58.6 \%$ (17) of endometriosis falls under the age group of 25-35 years.

Intraoperatively 18 patients needed blood transfusion and 2 of the case had to be converted to open laparotomy for dense adhesion and bleeding and second for the appendicular abscess. Most of the patients $(73 \%)$ were from nearby districts Jhapa, Morang, Sunsari.

\section{DISCUSSION}

The number of laparoscopic surgeries is also rising (123 vs 100) in this institute each year. ${ }^{3}$ This shows awareness, demand and availability of service. In this study, mean ages of the patients who underwent diagnostic laparoscopy and operative laparoscopy were $22.3 \pm 4.4$ and $34.3 \pm 10$ years respectively; and most of them were in 25-35 years age group which was similar to the study done in Nigeria $^{4}$, Kano ${ }^{5}$, Dhulikhel $\left(36.70 \pm 10.60\right.$ year ${ }^{6}$ 
and Kathmandu (25-34 years) ${ }^{7}$

In our study diagnostic procedures were only $6.5 \%$; subfertility with tubal pathology and endometriosis were two main reasons like in other studies. ${ }^{8,9}$

A total of 115 patients underwent laparoscopic operative intervention and among them the most common ovarian pathology in this study was dermoid cyst $(n=42,34 \%)$ followed by endometriosis $(n=29$, $23 \%)$ and cystadenoma $(n=25,20 \%)$. This is in contrast to the study done by Shaha $\mathrm{R}$ et $\mathrm{al}^{4}$ where endometriosis was the commonest ovarian pathology followed by dermoid; and other study done by Subedi $\mathrm{S}$ et $\mathrm{al}^{3}$ where endometriosis and cystadenoma were common. This was also in contrast with study by Grammatikakis ${ }^{10}$ where endometriosis was $80 \%$ of total 1522 and dermoid was only 60 (4\%). Study done by Yuen et $\mathrm{al}^{7}$ showed that endometriosis and dermoid cysts were two most common benign ovarian tumour; ovarian conserving surgery was in $70 \%$ whereas in our study it was $58 \%$ and salpingooophorectomy in $22 \%$ which was less than other study. ${ }^{3}$ The result of out study was also comparable with Parkar et $\mathrm{al}^{11}$ where $73.5 \%$ had cystectomy, $17.4 \%$ had oophorectomy and $6 \%$ had aspiration.

Due to lack of morcellator, only small pedunculated myoma were removed. Few of the endometriotic cyst were deroofed and punctured.

There was some degree of complication (16\%) like blood transfusion in 18 cases and conversion into open laparotomy in 2 cases similar to the report in Kenya by Parkar; ${ }^{12}$ and it was relatively less than other study by Bajracharya ${ }^{13}$, Golash ${ }^{14}(7 \%)$ and Jansen et $\mathrm{al}^{15}$ (4.5\% of diagnostic and $17.9 \%$ of operative laparoscopy) but more than Ikechebelu et $\mathrm{al}^{16}$ where it was only $0.12 \%$. A study done by Sokol et $\mathrm{al}^{17}$ also found that $6.3 \%$ of 2530 cases had converted to open laparotomy especially in cases with risk factor like surgeon inexperience, level of laparoscopic complexity, body mass index greater than $30 \mathrm{~kg} / \mathrm{m}^{2}$, history of laparotomy, presence of adhesion and intraoperative technical difficulty. In our study period, we did not have any vascular or visceral injury. Due to lack of morcellator, myomectomy for larger myomas were not performed.

\section{CONCLUSIONS}

The common pathologies found in laparoscopy were Dermoid cyst, endometriosis and cystadenoma. There was minimal complication like blood transfusion and few cases converted to open laparotomy.
There was no any visceral injury.

\section{REFERENCES}

1. Litynski GS. Laparoscopy-the early attempts: spotlighting Georg Kelling and Hans Christian Jacobaeus. JSLS. 1997;1(1):83-5.

2. SM P. Experience of laparoscopic sterilization under local anaesthesia in camps in Nepal. J Inst Med. 1984;6:31-6.

3. Subedi S, Gc N, Lamichhane S. Initial Experiences of Laparoscopic Surgery at Nobel Medical College Teaching Hospital: A Learning Curve. 2016;4(1):20-3. DOI: https:// doi.org/10.22502/jlmc.c4il.77

4. Constance E. Shehu, SB. A five-year audit of Gynecological laparoscopy at Usmanu Danfodiyo university teaching hospital, Sokoto, Nigeria. Eur J Pharm Med Res. 2016;3(7):76-81.

5. Efetie ER, Abubakar JS, Habeeb SA. Audit of gynaecological laparoscopies in National Hospital Abuja, Nigeria. Niger J Clin Pact. 2009;12 (6):149-52. PMID: 19764663.

6. Tamrakar SR, Dongol A, Shakya S, Kayastha B. Minimal Invasive Gynaecological Surgeries in Dhulikhel Hospital: One and Half Decade Long Experience. Kathmandu Univ Med J. 2018;64(4):333-7 PMID: 31729349.

7. Asmita Ghimire, Padam Raj Pant, Nilam Subedi, Samriddha Raj Pant. Trends of laparoscopic gynaecologic surgeries in a tertiary care centre: A five-year retrospective study. Grande Med J. 2019;1(1):26-30 DOI:10.3126/ gmj.v1i1.22402

8. Nasir S, Hassan M, Tanau K, Abubakar PA, Ahmed YUA. Experience with gynaecological laparoscopy in a tertiary hospital, North-West Nigeria. Orient J Med. 2014; 26:48-52

9. Saha R, Ns S, Thapa M, Shrestha J, Bajracharya J, Karki C. Experiences of Gynecological Laparoscopic Surgeries in a Teaching Hospital. J Nepal Health Res Counc. 2013;11(1):49-52.

10. Grammatikakis I, Trompoukis $\mathrm{P}$, Zervoudis S, Mavrelos C, Economides P, Tziortzioti V, et al. Laparoscopic Treatment of 1522 Adnexal Masses: An 8-Year Experience. Diag Therap Endoscop. 2015;2015(979162). DOI: $10.1155 / 2015 / 979162$ 
11.Parker J, Bethune M, Lau P, Permezel M, Tan J, Byrne D. (1996). Operative Laparoscopic Management of Adnexal Cysts: Initial Experience at the Royal Women's Hospital 1991-1994. Aus New Zeal J Obstet Gynaecol. 1996;36(1):3135. DOI:10.1111/j.1479-828x.1996.tb02918.x

12.Parkar RB, Thagana NG, Baraza R, Otieno D. Experience with laparoscopic surgery at the Aga Khan Hospital, Nairobi. East Afr Med J. 2003;80 (1):44-50. DOI: 10.4314/eamj.v80i1.8665

13.Bajracharya N, Dangal G, Karki A, Pradhan H, Shrestha R, Bhattachan K, et al. Experience of Laparoscopic Gynecological Surgeries at Kathmandu Model Hospital. Nep J Obstet Gynaecol. 2018;12(1):22-5. DOI: $\quad 10.3126 /$ njog.v12i1.18988

14.Golash V, Willson PD. Early laparoscopy as a routine procedure in the management of acute abdominal pain: a review of 1,320 patients. Surg Endosc. 2005;19(7):882-5.
15.Jansen WF, Kapitegyn K, Trimbose T, Hermans J. Complications of laparoscopy, a prospective multi centre observational study. Br J Obs Gyne. 1997;104(5):595-600. DOI: 10.1111/j.1471-0528.1997.tb11539.x

16.Ikechebelu J. Experience with diagnostic laparoscopy for gynaecological indications. Niger J Clin Pract. 2013;16(2):155-8. DOI: 10.4103/1119-3077.110129

17.Sokol AI, Chuang K, Milad MP. (2003). Risk Factors for Conversion to Laparotomy During Gynecological Laparoscopy. J Am Assoc Gynaecol Laparoscopists. 2003;10(4):46973. DOI:10.1016/s1074-3804(05)60146-6 